\title{
Boceprevir and personalized medicine in hepatitis $C$ virus infection
}

This article was published in the following Dove Press journal:

Pharmacogenomics and Personalized Medicine

25 September 2012

Number of times this article has been viewed

\author{
François Habersetzer ${ }^{1-3}$ \\ Céline Leboeuf ${ }^{2,3}$ \\ Michel Doffoël ${ }^{1-3}$ \\ Thomas F Baumert ${ }^{1-3}$ \\ 'Pôle Hépato-digestif, Hôpitaux \\ Universitaires de Strasbourg, \\ ${ }^{2}$ Université de Strasbourg, ${ }^{3}$ Inserm \\ 748, Strasbourg, France
}

Correspondence: François Habersetzer Pôle Hépato-digestif, Inserm 748, Université de Strasbourg, Nouvel Hôpital Civil, I Place de l'Hôpital, 6709I Strasbourg, France

Tel +33 369551009

Fax +33369551857

Email francois.habersetzer@chrustrasbourg.fr

\begin{abstract}
Boceprevir was the first agent, along with telaprevir, of a novel class of direct-acting antivirals that entered clinical practice for the treatment of chronic hepatitis $\mathrm{C}$. Boceprevir is an antiprotease that directly blocks hepatitis $\mathrm{C}$ virus (HCV) replication. Two studies in patients with HCV genotype 1 infection have shown that addition of boceprevir to the standard of care, ie, pegylated interferon-alfa (PEG-IFN- $\alpha$ ) and ribavirin, markedly increased the rate of sustained virological response. A sustained virological response was obtained in about $70 \%$ of patients who had never been treated, as well as in $69 \%-75 \%$ and $40 \%$ of previous relapsers and nonresponders to PEG-IFN- $\alpha$-ribavirin, respectively. Side effects were observed in almost all treated patients. Anemia, the most frequent adverse event related to administration of boceprevir, occurred in about $50 \%$ of patients. The decision to add boceprevir to the standard of care is made on an individual basis, and takes into account the prognosis of the liver disease, the efficacy of therapy, as it could be at best predicted, and the side effects that may arise, taking into account the comorbidities of the patient. Ultimately, the treatment must be accepted by the patient, who should fully understand the benefits and risks. Boceprevir trials were designed with the concept of individualized and response-guided therapy which establishes treatment decisions on how rapidly patients respond to treatment. Individualized therapy for chronic hepatitis $\mathrm{C}$ is based on patient and viral characteristics to make the best choice about whether a person will benefit from therapy and to evaluate on-treatment predictors of response to shorten therapy in patients with a rapid response as well as in patients who did not respond sufficiently to expect $\mathrm{HCV}$ eradication. This review focuses on the main results obtained so far, their impact on the treatment of patients with chronic hepatitis $\mathrm{C}$, and potential therapeutic perspectives.
\end{abstract}

Keywords: boceprevir, antiviral therapy, hepatitis $\mathrm{C}$ virus

\section{History of HCV infection and antiviral therapy}

Hepatitis C virus (HCV) was identified by Choo et al in 1989 (Figure 1). ${ }^{1} \mathrm{HCV}$ infection is a major health problem and a leading cause of liver disease. More than 140-170 million people worldwide are chronically infected. ${ }^{2,3}$ In the United States, it is estimated that $1.3 \%$ or 3.2 million people have chronic $\mathrm{HCV}$ infection. ${ }^{4} \mathrm{HCV}$ is an enveloped hepatotropic, positive-stranded RNA virus of approximately $9.6 \mathrm{~kb}$. $\mathrm{HCV}$ is highly variable and six major genotypes have been described. ${ }^{5}$ Hepatitis $\mathrm{C}$ is transmitted primarily by the parenteral route, and sources of infection include injection drug use, and transfusions of blood or blood-derived products. The virus infects liver cells and can cause acute hepatitis, with severe inflammation of the liver and longterm complications when infection persists. In fact, in the majority $(70 \%-80 \%)$ of people, $\mathrm{HCV}$ infection persists, leading to chronic hepatic infection that can progress 
to cirrhosis and liver cancer. ${ }^{2,6}$ In patients with chronic $\mathrm{HCV}$ infection, the risk of developing cirrhosis ranges from $5 \%$ to $25 \%$ over periods of 25-30 years. Patients with cirrhosis have increased risk of hepatic decompensation (30\% over 10 years) and hepatocellular carcinoma ( $1 \%-3 \%$ per year). ${ }^{7}$ So far, there is no vaccine to prevent infection.

The goal of anti-HCV therapy is to prevent complications from $\mathrm{HCV}$ infection and death. ${ }^{7}$ Milestones in $\mathrm{HCV}$ research and therapy are represented in Figure 1. Interferon-alfa (IFN$\alpha$ ) was first shown in 1986 to have beneficial effects for the treatment of chronic non A-non B hepatitis as indicated by improvement in alanine transferase values and liver histology. ${ }^{8}$ It was shown later that these beneficial effects were associated with a decrease in serum HCV RNA and that a long-term response was associated with sustained undetectability of serum HCV RNA. Following these initial results, it has been shown that a sustained virological response, ie, disappearance of serum HCV RNA during treatment and maintenance of the response 6 months after discontinuation of treatment, was associated with improvement in liver damage with a decrease in inflammation and hepatic fibrosis as assessed by serial liver biopsies. ${ }^{9}$ Because of the slow evolution of chronic HCV infection over several decades, it has been difficult to demonstrate that treatment improves survival, although retrospective and uncontrolled studies have suggested a benefit. ${ }^{10,11}$ IFN- $\alpha$ does not act directly on HCV itself but exerts its antiviral activity through a cell membrane receptor, thereby activating IFN-stimulating genes that in turn will have intracellular antiviral effects. ${ }^{12}$ It is unclear whether IFN- $\alpha$, through its immunomodulatory properties, accelerates the clearance of infected cells at the same time as it inhibits viral replication. ${ }^{13}$ Another major advance in the treatment of chronic $\mathrm{HCV}$ infection was highlighting of the increased efficacy of the combination of IFN- $\alpha$ and ribavirin, a nucleotide analog with a broad spectrum of activity against RNA and DNA viruses, compared with IFN- $\alpha$ as monotherapy. Like IFN- $\alpha$, ribavirin was used empirically in 1991 for the treatment of chronic hepatitis C. ${ }^{14}$ Initially, a reduction in alanine transferase values during ribavirin therapy was interpreted as a beneficial effect, but subsequent studies did not show a decrease in HCV RNA in treated patients. ${ }^{15}$ Nevertheless, a study combining IFN- $\alpha$ and ribavirin was performed in patients with chronic hepatitis C. This study showed significantly higher efficacy of the combination therapy compared with IFN- $\alpha$ monotherapy. ${ }^{16}$ These results were thereafter confirmed, amending the care of patients with chronic hepatitis $\mathrm{C} .{ }^{17}$ The results of combination therapy were subsequently improved by pegylation of IFN- $\alpha$ molecules in order to improve their pharmacokinetic and pharmacodynamic properties and to enhance their efficacy. ${ }^{13}$ Since 2001, the standard of care for the treatment of chronic hepatitis $\mathrm{C}$ from all genotypes combines pegylated IFN- $\alpha$ (PEG-IFN- $\alpha$ ) and ribavirin. While a sustained virological response can be achieved in $70 \%-90 \%$ of patients infected with genotype 2 or 3 , only about $50 \%$ of patients infected with genotype 1 or 4 achieve a sustained virological response after standard of care therapy. ${ }^{7}$ Thus, novel therapeutic strategies are urgently needed. Recent efforts to improve patient outcomes have mainly focused on antiviral therapy targeting virally encoded proteins or direct-acting antiviral agents.

\section{Development of direct-acting antiviral agents}

$\mathrm{HCV}$ is difficult to grow in cell culture, and the absence of robust cell culture models has long hampered the development

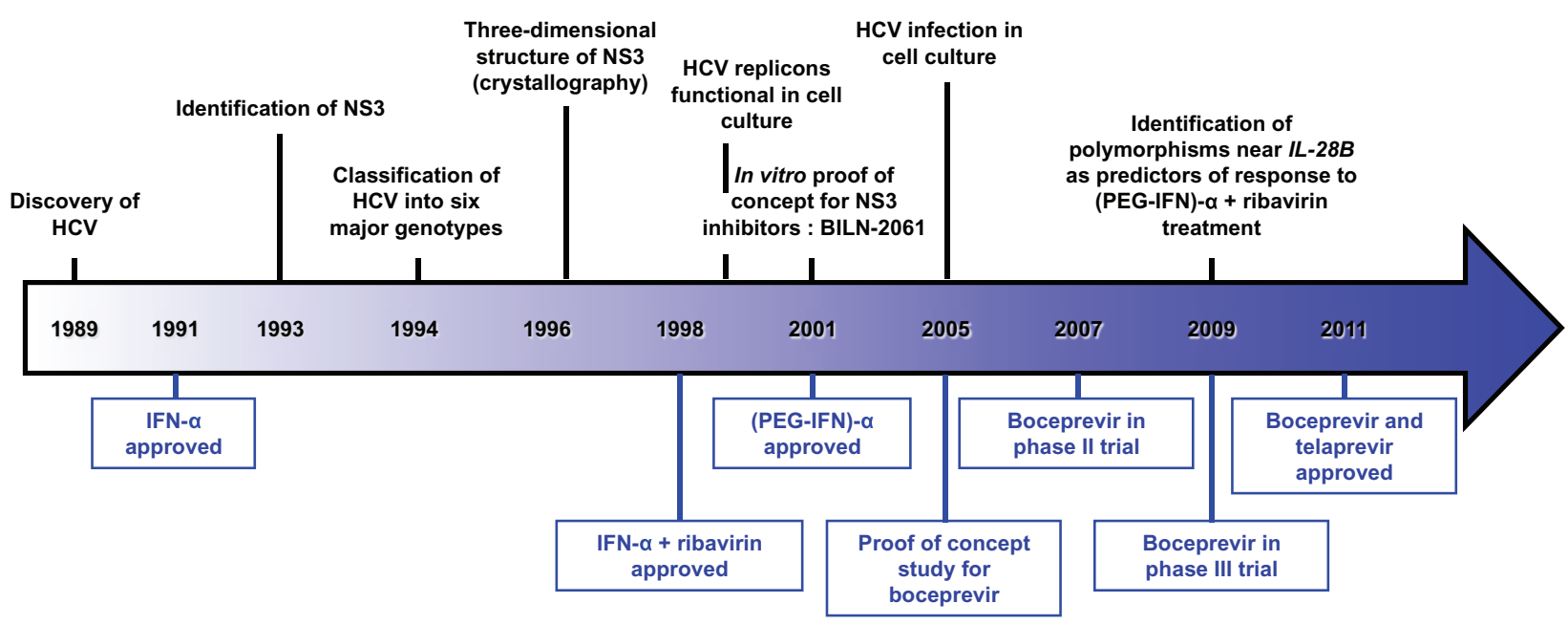

Figure I Milestones in HCV research and Direct-Acting Antivirals development.

Abbreviations: HCV, hepatitis C virus; NS3, non-structural protein 3; IFN- $\alpha$, interferon-alpha; PEG-IFN- $\alpha$, pegylated IFN- $\alpha$. 
of novel antivirals. The development of the replicon model in $1999^{18}$ allowed significant progress to be made in the understanding of the mechanism of HCV replication, and thereby enabled development of specific antivirals with a direct action on HCV. After its entry into the hepatocyte, the HCV RNA genome serves as a template for cap-independent translation through its $5^{\prime}$ internal ribosome entry site. The resulting 3000 amino acid polyprotein undergoes proteolytic maturation by host-encoded and virally-encoded proteases, giving rise to three structural proteins (core, E1, and E2), the viroprotein p7, and six nonstructural proteins (NS2, NS3, NS4A, NS4B, NS5A, and NS5B), as reviewed by Lindenbach and Rice. ${ }^{19}$ The nonstructural proteins coordinate the intracellular processes of the life cycle of the virus. The NS3 protease, located in the N-terminal third of the NS3 protein, forms a heterodimeric complex with the NS4A protein, a cofactor essential for the activity of NS3. NS3 encodes a chymotrypsin-like serine protease that is responsible for the cleavage of the NS3/4A, NS4A/4B, NS4B/5A, and NS5A/5B junctions. ${ }^{19}$ Therefore, the RNA helicase/protease NS3 plays a central role in the RNA replication of $\mathrm{HCV}$, and thus appears to be an important drug target for the treatment of HCV infection. Given the knowledge gained from the development of drugs to treat the human immunodeficiency virus (HIV) infection, research has been focused on the development of drugs inhibiting the HCV NS3 protease with the promise to block viral replication. Characterization of the atomic structure of NS3 in 1996 provided the necessary detailed insight to allow the design of NS3 inhibitors. ${ }^{20,21}$ BILN-2061 was the first NS3 protease inhibitor investigated in clinical studies that showed a marked antiviral effect in genotype 1-infected patients after two days of therapy. ${ }^{22}$ However, further development of BILN-2061 was stopped due to cardiac toxicity in animals. In recent years, several other NS3 protease inhibitors have been designed and assessed in clinical trials, including boceprevir and telaprevir.

\section{Boceprevir, a direct-acting antiviral for chronic HCV infection}

Boceprevir and telaprevir were the first NS3 protease inhibitors that allowed significant improvement in the treatment of chronic hepatitis $\mathrm{C}$. Boceprevir is a carboxamidebased oral $\mathrm{HCV}$ NS3/4A genotype 1 protease inhibitor. ${ }^{23}$ Boceprevir provides effective inhibition by formation of a stable, covalent, and reversible complex with the viral enzyme. Initial evaluation of boceprevir was assessed in the $\mathrm{HCV}$ subgenomic replicon system. Continuous exposure of replicon-bearing cell lines to boceprevir for 15 days resulted in a $1.5-\log$ to $2-\log$ decline in RNA levels at 72 hours and a $3.5-\log$ to $4-\log$ reduction by day $15 .^{23}$ The combination of boceprevir with IFN- $\alpha$ was more effective in suppressing HCV replication than either compound alone indicating synergy between these two antivirals. ${ }^{23}$ Furthermore, in this system, no toxicity towards hepatoma cells was observed. These promising in vitro data enabled boceprevir to enter clinical development.

\section{Pharmacokinetics and drug interactions \\ Absorption and metabolism}

Few pharmacokinetic data are available for boceprevir except those provided by the manufacturer (Merck, Whitehouse Station, NJ). ${ }^{24}$ Boceprevir is an orally bioavailable molecule with a short half-life of 3.4 hours, requiring its administration three times a day. After administration, the drug is rapidly absorbed, with a maximal concentration reached in approximately 2 hours. Liver impairment has been shown to be related to a maximum concentration increase of $28 \%$ and $62 \%$ in patients with moderate (Child-Pugh B) and severe hepatic failure (Child-Pugh C), respectively, in comparison with normal subjects. ${ }^{24}$ End-stage renal disease requiring hemodialysis is associated with a mild decrease in the area under the concentration-time curve (AUC). ${ }^{24}$ Food enhances absorption by up to $60 \%$ without effect of meal type or timing in comparison with food intake (high-fat or low-fat). ${ }^{24}$ Neither gender, race, nor age (19-65 years) seem to have an impact on the pharmacokinetics of boceprevir. ${ }^{24}$ An increasing trend of anemia with an increasing boceprevir AUC has been reported. ${ }^{25}$ Boceprevir is primarily metabolized by the aldoketoreductase-mediated pathway to inactive ketone metabolites. Boceprevir is also metabolized by cytochrome P450 (CYP)3A4/5, which allows formation of oxidative metabolites, and is in addition an inhibitor of this enzyme. ${ }^{26}$ Moreover, boceprevir is a substrate and inhibitor of the drug transporter, P-glycoprotein. ${ }^{24}$

\section{Drug interactions}

Drug interactions may increase drug toxicity or decrease drug effectiveness (Table 1). Sixty percent of medications are metabolized by CYP3A. As a consequence, there are many interactions to consider with boceprevir. ${ }^{27} \mathrm{CYP} 3 \mathrm{~A}$ inducers, such as rifampicin, strongly reduce boceprevir exposure and therefore could be responsible for treatment failure. Furthermore, boceprevir concentration can be strongly increased by CYP3A inhibitors, such as ketoconazole, resulting in enhancement of boceprevir-mediated adverse effects. 
Table I Example of drug interactions with boceprevir and side effects

\begin{tabular}{|c|c|c|c|}
\hline Class & Example of drug & Drug-drug interactions & Adverse effects \\
\hline Immunosuppressants & Tacrolimus* & Boceprevir $\uparrow$ [tacrolimus] & Nephro- and neurotoxicity, hypertension \\
\hline Antiretrovirals & Efavirenz* & Efavirenz $\downarrow$ [boceprevir] & Decreased efficacy of HCV treatment \\
\hline \multirow[t]{2}{*}{ Antimycobacterials } & Rifabutin* & Rifabutin $\downarrow$ [boceprevir] & Decreased efficacy of $\mathrm{HCV}$ treatment \\
\hline & & Boceprevir $\uparrow$ [rifabutin] & \\
\hline HMG-CoA reductase inhibitors & Atorvastatin & Boceprevir $\uparrow$ [atorvastatin] & Myopathy (rhabdomyolysis) \\
\hline Oral contraceptive & Drosperinone & Boceprevir $\uparrow$ [drosperinone] & Hyperkalemia \\
\hline Antidepressants & Trazodone & Boceprevir $\uparrow$ [trazodone] & Dizziness, hypotension, syncope \\
\hline Antipsychotics & Pimozide & Boceprevir $\uparrow$ [pimozide] & Cardiac arrhythmia \\
\hline Anxiolytics and sleep aids & Midazolam & Boceprevir $\uparrow$ [midazolam] & Sedation/respiratory depression \\
\hline Opioid replacements & Methadone & Boceprevir $\uparrow$ or $\downarrow$ [methadone] & Nausea, diarrhea, difficulty breathing \\
\hline
\end{tabular}

Notes: All these drugs need to be used with caution and their dose have to be adapted. *Concomitant use with boceprevir is not recommended.

Data obtained from. ${ }^{24,28,61,62,63}$

Abbreviations: $\mathrm{HCV}$, hepatitis C virus; HMG-CoA reductase inhibitor, 3-hydroxy-3-methyl-glutaryl-CoA reductase inhibitor.

In treatment of HIV, ritonavir is used to inhibit CYP3Amediated metabolism of other HIV protease inhibitors in order to increase their exposure to achieve a prolonged therapeutic effect. This strategy has been tested for boceprevir but unfortunately failed. ${ }^{28}$ Because boceprevir is metabolized by CYP3A $4 / 5$ but is also a strong inhibitor of this cytochrome, the administration of drugs metabolized by CYP3A4/5 (eg, midazolam, a sedative drug) in association with boceprevir could prolong their therapeutic and/or adverse effects. ${ }^{24}$

Drug interactions between boceprevir and antiretroviral therapy remain to be investigated, given the high proportion of patients coinfected with HCV and HIV. Among the antiretroviral drugs, it has been shown that efavirenz reduces boceprevir concentrations, while tenofovir slightly increases its concentrations. In $\mathrm{HCV}$-infected patients undergoing liver transplantation, the combination of boceprevir and immunosuppressive drugs has to be tightly controlled. Indeed, boceprevir slows down the clearance of cyclosporine A and tacrolimus, but neither of these immunosuppressive drugs has an effect on the metabolism of boceprevir. Furthermore, other classes of drugs, such as oral contraceptives (eg, drosperinone), antidepressants (eg, escitalopram), or corticosteroids (eg, dexamethasone) have to be avoided or used with caution because drug interactions with boceprevir have been identified. ${ }^{24,28}$ Thus, a careful evaluation of drugs administered to patients who are likely to be treated with boceprevir is very important to avoid side effects, reduced efficacy of antiviral therapy, or another medication that will have its effectiveness reduced if its metabolism is impaired (Table 1).

\section{Clinical development}

\section{Initial phase I and II studies}

In 2005, a proof-of-concept, dose-escalating study over 14 days showed that boceprevir monotherapy had a dose- related antiviral effect in patients with the HCV genotype 1 who did not respond to previous IFN- $\alpha$ therapy. ${ }^{29}$ However, subsequent emergence of HCV-resistant strains in clinical trials using boceprevir alone limited the use of this directacting antiviral agent as monotherapy. ${ }^{30,31}$ Indeed, the rapid viral kinetics and quasispecies distribution of HCV allowed emergence of resistant viral strains during antiviral therapy. ${ }^{32}$ In a further Phase I study in HCV-infected patients who were nonresponsive to PEG-IFN- $\alpha$, the combination of boceprevir and PEG-IFN- $\alpha$ resulted in a more important reduction in $\mathrm{HCV}$ viral load in comparison with boceprevir or PEG-IFN- $\alpha$ administered as monotherapy. ${ }^{33}$ Phase II studies were then conducted in treatment naïve-patients and in nonresponders to the standard of care combining PEG-IFN- $\alpha$ and ribavirin. In treatment-naive patients, a Phase II study $(\mathrm{n}=595)$ combined boceprevir with the standard of care in patients with HCV genotype 1 infection under several modalities. This study compared triple therapy of variable duration preceded or not preceded by 4 weeks of pretreatment with PEG-IFN$\alpha$-ribavirin. In addition, a group of patients received triple therapy with low doses of ribavirin to improve the tolerability of treatment. The highest sustained virological response rate was observed in patients receiving 44 weeks of triple therapy preceded by a 4-week standard of care (lead-in period). This regimen increased the treatment efficacy by two-fold as compared with patients receiving the standard of care. Indeed, $38 \%$ versus $75 \%$ of patients had a sustained virological response with double therapy and triple therapy, respectively. ${ }^{34}$ A placebo-controlled randomized Phase II study was also conducted in $\mathrm{HCV}$-infected patients who were nonresponders to previous standard of care therapy. In this trial, low doses of boceprevir were administered and the study included arms without ribavirin. The results showed only a slight increase in sustained virological response in $7 \%-14 \%$ 
of patients treated with boceprevir and PEG-IFN- $\alpha$-ribavirin compared with $2 \%$ in the control group, ${ }^{35}$ indicating the lack of efficacy of low-dose boceprevir in combination with standard of care. These results showed that, in these difficultto-treat patients, boceprevir should be administered at higher doses, in combination with standard care at an optimal dosage to achieve optimal results.

\section{Clinical development in Phase III studies}

The efficacy and tolerance of boceprevir were studied in two Phase III studies in combination with PEG-IFN- $\alpha$ ribavirin for treatment of chronic hepatitis $\mathrm{C}$ in genotype 1 -infected patients. These Phase III trials were either conducted in treatment-naïve subjects, ie, the SPRINT-2 (Serine Protease Inhibitor Therapy-2) study, or in subjects who had previously failed PEG-IFN- $\alpha$-ribavirin therapy, ie, the HCV RESPOND-2 (Retreatment with HCV Serine Protease Inhibitor Boceprevir and PegIntron/Rebetol 2) study. Inclusion and exclusion criteria were the same in both studies, and exclusion criteria comprised in particular HIV infection, decompensated cirrhosis, hepatocellular carcinoma, chronic hepatitis $\mathrm{B}$, and renal insufficiency. ${ }^{36,37}$ In both trials, the primary endpoint was sustained virological response, measured 24 weeks after the end of therapy. Plasma HCV RNA levels were measured using the TaqMan
2.0 assay, the lower limits of quantification and detection of which are $25 \mathrm{IU} / \mathrm{mL}$ and $9.3 \mathrm{IU} / \mathrm{mL}$, respectively; the lower limit of detection was used for decision-making at various points during the study. ${ }^{36,37}$ The results of the two Phase III trials were published at the same time in March 2011. The treatment regimen was identical in both studies, except for the treatment duration of triple therapy that was longer in patients previously treated with standard of care than in treatment naïve-patients (Figure 2). In both trials, PEG-IFN- $\alpha$ was administered subcutaneously at a dose of $1.5 \mu \mathrm{g} / \mathrm{kg}$ of body weight once weekly, and weight-based oral ribavirin was administered as 600-1400 mg/day in two divided doses. Treatment with boceprevir consisted of oral administration of $800 \mathrm{mg}$ three times daily in four capsules of $200 \mathrm{mg}$ each, to be taken every 7-9 hours with a light meal.

\section{Efficacy in treatment-naive patients}

The treatment-naïve patient trial (SPRINT-2) was a doubleblind study in which previously untreated adult patients with HCV genotype 1 infection were randomly assigned to one of three groups (Figure 2). In order to enroll more black subjects, two separate population cohorts were formed which enrolled nonblack and black subjects. The patients were randomized to one of the three treatment groups after stratification according to baseline HCV RNA levels and HCV genotype 1 subtypes

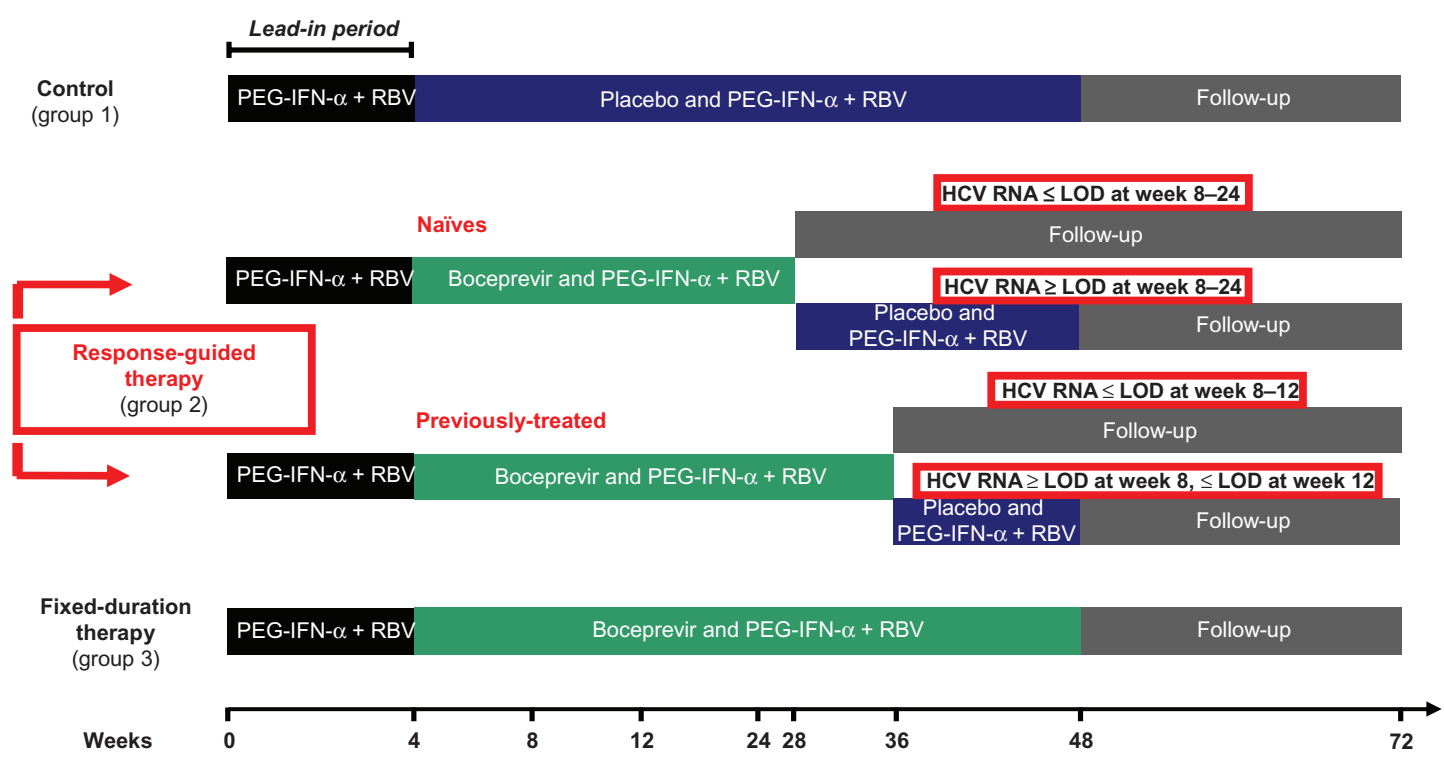

Figure 2 Phase III trials design.

Notes: Patients from SPRINT-2 (naïve patients) and RESPOND-2 (previously-treated patients) studies were randomly divided into 3 groups. All subjects received PEG-IFN- $\alpha+$ RBV for 4 weeks (lead-in period). Then, patients were administered with: PEG-IFN- $\alpha+$ RBV and placebo for 44 weeks: control group; PEG-IFN- $\alpha+$ RBV and boceprevir for 44 weeks: fixed-duration therapy group; PEG-IFN- $\alpha+$ RBV and boceprevir for 28 (naïve patients) or 36 (previously-treated patients) weeks: response-guided therapy group. Subjects with a detectable viral load at weeks 8 and 24 (naïve patients) or at week 8 (previously-treated patients) received PEG-IFN- $\alpha+$ RBV and placebo until week 48. Treatment failure was considered for previously-treated patients with a detectable viral load at week 12 , resulting in discontinuation of the treatment. All other patients were followed-up until week 72. Adapted from Poordad et al and Bacon et al. .6,37 $^{36}$

Abbreviations: HCV, hepatitis C virus; PEG-IFN- $\alpha$, pegylated interferon-alpha; RBV, ribavirin; LOD, limit of detection. 
$1 \mathrm{a}$ and $1 \mathrm{~b}$. All patients received PEG-IFN- $\alpha$ during the 4-week lead-in period (Figure 2). Subsequently, the control group received placebo and PEG-IFN- $\alpha$-ribavirin for 44 weeks; group 2 (response-guided therapy) received boceprevir and PEG-IFN- $\alpha$-ribavirin for 24 weeks after the lead-in period. Treatment with PEG-IFN- $\alpha$-ribavirin was continued for 44 weeks in patients with a detectable HCV RNA level between weeks 8 and 24 (absence of extended rapid virological response); and group 3 (fixed-duration therapy) received boceprevir and PEG-IFN- $\alpha$-ribavirin for 44 weeks. The patients were followed after the end of therapy until week 72 . Nonblack and black patients were analyzed separately.

A total of 1097 patients were included in this study, comprising 938 nonblack and 156 black patients. In the nonblack cohort, sustained virological response rates were $40 \%$ in the control group, $67 \%$ in group 2 (response-guided therapy), and 68\% in group 3 (fixed-duration therapy, Table 2). The corresponding sustained virological response rates in black patients were $23 \%, 42 \%$, and $53 \%$ for groups 1,2 , and 3 , respectively (Table 2 ). In both groups (black and nonblack patients) treated with boceprevir, response rates were significantly higher in comparison with the control group (Table 2). Importantly, in nonblack patients, response-guided therapy with individualized treatment ( 24 weeks of triple therapy in the event of absence of detectable HCV RNA at weeks 8 and 24) resulted in similar rates of sustained virological response in comparison with the fixed-duration group receiving triple therapy for 48 weeks (Table 2). In total, 97\% of patients on response-guided therapy with an extended rapid virological response achieved a sustained virological response similar to that of group 3 patients treated for 48 weeks with triple therapy, with a sustained virological response in $96 \%$ of cases.
This high rate of response observed in patients on responseguided therapy avoided the need for further administration of therapy and, importantly, precluded exposure to side effects without loss of the chance of eliminating HCV infection. The undetectability of HCV RNA in serum at week 8 was highly predictive of a sustained virological response in all three groups of patients, with rates of $85 \%, 88 \%$, and $90 \%$ for groups 1,2 , and 3 , respectively. In patients who responded well to PEGIFN- $\alpha$-ribavirin combination therapy, addition of boceprevir did not increase the sustained virological response rate. Thus, triple therapy with its unnecessary side effects and costs may be avoided in these patients, although an advantage would be to shorten the treatment duration. Patients with a poor response to PEG-IFN- $\alpha$-ribavirin (reduction of viral load $<1 \log _{10}$ IU/ $\mathrm{mL}$ after 4 weeks of therapy) had a higher response than the control group (sustained virological response rates were $5 \%$ in the control group, $29 \%$ in the response-guided therapy group, and $39 \%$ in the fixed-duration therapy group) but, overall, the response rate was markedly reduced and appeared to be higher upon longer exposure to the triple therapy regimen in these more difficult-to-treat patients. In addition, higher rates of boceprevir-resistant strains were observed, which may have had a negative impact on subsequent treatment with another antiviral drug regimen in the event of failure on triple therapy. These patients may benefit from improved therapy once new antivirals become available and if treated with more reinforced monitoring of the virological response. Analysis of factors predicting response have shown that for boceprevir, a baseline HCV RNA level below 400,000 IU/mL, age younger than 40 years, absence of cirrhosis, and nonblack ethnicity were predictors of a sustained virological response (Table 3). ${ }^{36}$ In patients with cirrhosis, the response was not different between

Table 2 SVR rates according to treatment group and cohorts in phase III clinical trials

\begin{tabular}{lllll}
\hline Trial & Cohort & $\begin{array}{l}\text { Control } \\
\text { (group I) }\end{array}$ & $\begin{array}{l}\text { Response-guided therapy } \\
\text { (group 2) }\end{array}$ & $\begin{array}{l}\text { Fixed-duration therapy } \\
\text { (group 3) }\end{array}$ \\
\hline $\begin{array}{l}\text { SPRINT-2 } \\
\quad \text { Naïve patients }\end{array}$ & Non-black cohort & $40 \%$ & $67 \%$ & $68 \%$ \\
& Black cohort & $23 \%$ & $42 \%$ & $53 \%$ \\
& Combined cohorts & $38 \%$ & $63 \%$ & $66 \%$ \\
RESPOND-2 & & & & $75 \%$ \\
$\quad$ Previously-treated patients & Prior relapse & $29 \%$ & $69 \%$ & $52 \%$ \\
& Prior nonresponse & $7 \%$ & $40 \%$ & $34 \%$ \\
& Poor response to lead-in & $0 \%$ & $33 \%$ & $79 \%$ \\
& Good response to lead-in & $25 \%$ & $73 \%$ & $66 \%$ \\
\hline
\end{tabular}

Notes: Prior relapse corresponds to an undetectable viral load at the end of prior therapy but without achieving SVR. Prior nonresponse corresponds to a reduction of viral load of at least $2 \log _{10} \mathrm{IU} / \mathrm{mL}$ with then the persistance of detectable HCV RNA during follow-up. Poor response to PEG-IFN- $\alpha$ corresponds to a reduction of viral load of less than I $\log _{10} \mathrm{IU} / \mathrm{mL}$ after the lead-in period. Good response to PEG-IFN- $\alpha$ corresponds to a reduction of viral load greater than I log 10 IU:mL after the lead-in period. Data drawn from Poordad et al and Bacon et al. ${ }^{36,37}$

Abbreviations: HCV, hepatitis C virus; SVR, Sustained Virological Response; PEG-IFN- $\alpha$, pegylated interferon-alpha. 
the boceprevir and control groups, but sample sizes were small and further evaluation is needed. Furthermore, as observed for telaprevir, the response was better in patients infected with HCV subtype $1 \mathrm{a}$ than in those with subtype $1 \mathrm{~b}$ (Table 3 ). ${ }^{38}$

\section{Efficacy in previously treated patients}

Triple therapy with PEG-IFN- $\alpha$-ribavirin and boceprevir was evaluated in the RESPOND-2 trial in previous nonresponders (two-third of patients) or relapsers (one third of patients) after PEG-IFN- $\alpha$-ribavirin standard of care. ${ }^{37}$ The sustained virological response rate was higher in patients treated with boceprevir in combination with standard of care than in the control group (Table 2). Responses were similar for patients on fixed-duration therapy and on response-guided therapy, with rapid disappearance of serum HCV RNA, as assessed after 8 weeks of treatment. In these patients, sustained virological response rates were very high at $86 \%$ after 32 weeks of triple therapy (response-guided therapy group) and $88 \%$ after 44 weeks of triple therapy (fixed-duration therapy group). In contrast, patients who responded poorly to lead-in PEG-IFN$\alpha$-ribavirin treatment (reduction of viral load $<1 \log _{10} \mathrm{IU} / \mathrm{mL}$ ) had a markedly reduced response to triple therapy. Patients with prior relapse after PEG-IFN- $\alpha$-ribavirin therapy had a higher response rate than those with previous nonresponse. The sustained virological response rate after triple therapy was $69 \%$ and $75 \%$ in prior relapsers in the response-guided therapy group and fixed-duration therapy group, respectively, and $40 \%$ and $52 \%$ in prior nonresponders in the response-guided therapy group and fixed-duration therapy group, respectively (Table 2). ${ }^{37}$ With regard to treatment-naïve patients, the results overall indicated that an early response identifies patients in whom a shorter treatment period is sufficient enough to stop therapy early and avoid further potential side effects. Interestingly, preliminary results from the intermediate analysis of a Phase III study which enrolled nonresponders to PEG-IFN- $\alpha$-ribavirin from previous Phase II and III trials demonstrated a sustained virological response rate of $40 \%,{ }^{39}$ indicating that a significant number of the most difficult-totreat patients could benefit from triple therapy.

Reducing the treatment duration may not only prevent unnecessary side effects but also avoid development of resistant viral quasispecies that emerge during therapy in nonresponders. It has been shown that after discontinuation of therapy, there is a return to the initial viral population levels suggesting that patients could be retreated in the near future by interferon-free regimens combining different direct-acting antiviral agents that include a protease inhibitor. ${ }^{40}$ Consequently, it seems important to prevent development of resistant strains, although this has not been assessed to date. Post hoc analyses of the SPRINT-2 and RESPOND-2 studies have shown that combination of serum HCV RNA $\geq 100 \mathrm{IU} / \mathrm{mL}$ at week 12 after starting therapy and detectable serum HCV RNA at week 24 of treatment allow the best stopping rules to avoid unnecessarily prolonging treatment (which if continued will not be effective) and to stop too early a treatment (that still allow, if continued, a viral eradication). (Figure 3). ${ }^{41}$

\section{Side effects}

The most common adverse events reported with triple therapy combining standard of care and boceprevir were flu-like symptoms, which are characteristic of PEG-IFN- $\alpha$. Serious adverse events were reported at a rate of about $10 \%$ in patients

Table 3 Predictive factors of SVR in naïve and previously non-responders patients in phase III clinical trials

\begin{tabular}{|c|c|c|c|}
\hline Trial & Variable & Odds ratio $(95 \% \mathrm{Cl})$ & $P$ value \\
\hline \multicolumn{4}{|l|}{ SPRINT-2 } \\
\hline \multirow[t]{9}{*}{ Naïve patients } & Age $\leq 40$ vs $>40$ years & $1.5(1.0-2.1)$ & 0.03 \\
\hline & No cirrhosis vs cirrhosis & $2.5(1.4-4.6)$ & 0.003 \\
\hline & Black vs nonblack cohort & $0.5(0.3-0.7)$ & $<0.001$ \\
\hline & IL28B genotype: CC vs TT* & $2.6(1.3-5.1)$ & 0.006 \\
\hline & $\mathrm{CC}$ vs $\mathrm{CT}^{*}$ & $2.1(1.2-3.7)$ & 0.01 \\
\hline & Statin use vs no statin use & $3.4(1.1-10.7)$ & 0.04 \\
\hline & HCV genotype: Ib vs Ia* & $2.0(1.2-3.4)$ & 0.005 \\
\hline & Baseline viral load $\leq 400,000$ vs $>400,000 \mathrm{lU} / \mathrm{mL}$ & $3.9(2.1-7.1)$ & $<0.001$ \\
\hline & Decline in viral load at week 4 ( $\geq I$ vs $<1 \log _{10}$ decline) & $9.0(6.3-12.8)$ & $<0.001$ \\
\hline \multicolumn{4}{|l|}{ RESPOND-2 } \\
\hline \multirow[t]{3}{*}{ Previously-treated patients } & Previous relapse vs previous non-response & $3.2(1.9-5.4)$ & $<0.001$ \\
\hline & Baseline viral load $\leq 800,000$ vs $>800,000 \mathrm{IU} / \mathrm{mL}$ & $2.4(1.1-5.3)$ & 0.04 \\
\hline & Decline in viral load at week 4 ( $\geq I$ vs $<1 \log _{10}$ decline) & $5.2(\mathrm{NC}-\mathrm{NC})$ & $<0.001$ \\
\hline
\end{tabular}

Note: *Data obtained retrospectively.

Data obtained from ${ }^{36,37,46}$.

Abbreviations: HCV, hepatitis C virus; SVR, Sustained Virological Response; Cl, confidence interval; NC, not communicated. 


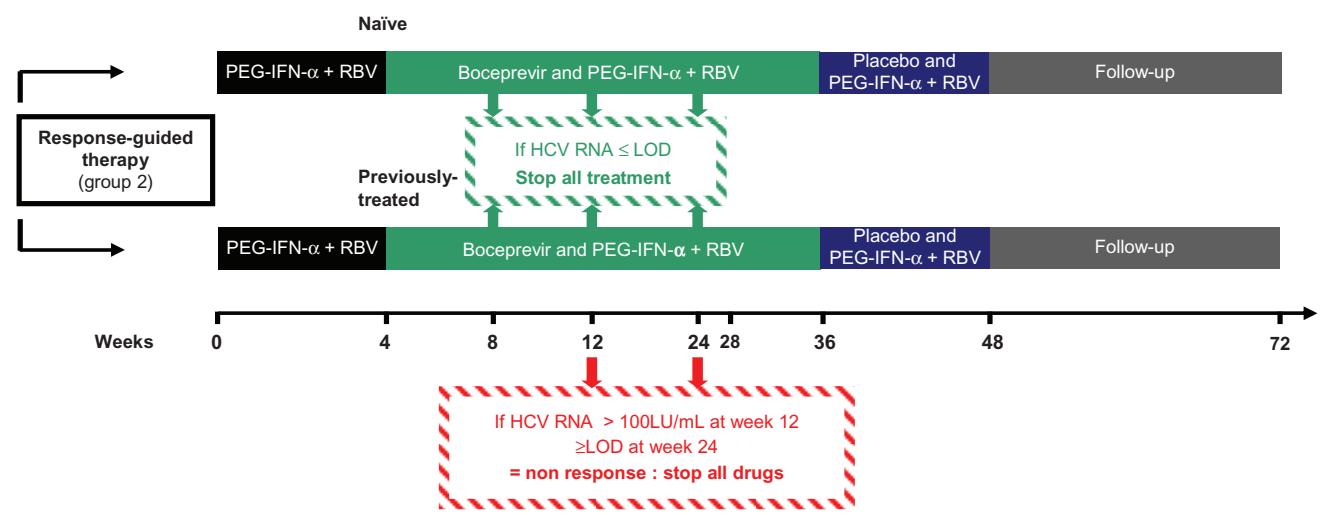

Figure 3 Duration of therapy following the registration of boceprevir by the FDA and stopping rules during boceprevir treatment in naïve and previously treated patients with response-guided therapy.

Notes: Both naïve and previously-treated patients are tested for viral load at days 8, 12 and 24 to determine whether therapy is continued or not. Although boceprevir treatment of naive patients without an eRVR was stopped at day 28 in the SPRINT-2 trial, the FDA recommends these patients to be treated with boceprevir until week 36. Data obtained from ${ }^{60}$.

Abbreviations: HCV, hepatitis C virus; PEG-IFN- $\alpha$, pegylated interferon-alpha; RBV, ribavirin; LOD, limit of detection.

treated for the first time, with no differences between the treatment groups (Table 4). In patients previously exposed to PEG-IFN- $\alpha$-ribavirin, adverse events occurred more frequently in those treated with triple therapy (Table 4). In addition to the common side effects occurring on PEG-IFN$\alpha$-ribavirin, patients treated with boceprevir had significantly more dysgeusia, rash, dry skin, anemia, and absolute neutrophil count below $750 / \mathrm{mm}^{3}$ (Table 5) ${ }^{36,37}$ No differences between the boceprevir treatment groups were observed. However, although the differences were mild, treatment had to be discontinued or modified more often in patients enrolled in the boceprevir arms than in the control group.

\section{Pharmacogenomics}

\section{Role of IL28B}

Taking into account the individual profile of the patient to make the best therapeutic choice appears critical to establishing the most acceptable risk-to-benefit balance. Individual genetic background may influence the response to therapy as well as occurrence of side effects, because it has been shown that response to standard of care depends on race and ethnicity. Indeed, a significant difference in treatment efficacy with PEG-IFN- $\alpha$-ribavirin was observed between Caucasian American and African American patients, the latter showing a lower response to therapy in comparison with Caucasian Americans. ${ }^{42}$ Analysis of whole-genome single nucleotide polymorphism profiles has shown that a single nucleotide polymorphism near the interleukin-28B (IL28B) gene is associated with response to PEG-IFN- $\alpha$-ribavirin treatment for chronic hepatitis $C$ as well as with spontaneous clearance of $\mathrm{HCV}^{43,44} I L-28 B$ polymorphism has been shown to be the strongest baseline predictor of a sustained virological response using PEGIFN- $\alpha$-ribavirin. ${ }^{45}$ In Caucasians, the CC IL-28B type was

Table 4 Types of adverse events according to treatment group in phase III clinical trials

\begin{tabular}{|c|c|c|c|c|}
\hline Trial & Events & $\begin{array}{l}\text { Control } \\
\text { (group I) }\end{array}$ & $\begin{array}{l}\text { Response-guided therapy } \\
\text { (group 2) }\end{array}$ & $\begin{array}{l}\text { Fixed-duration therapy } \\
\text { (group 3) }\end{array}$ \\
\hline \multicolumn{5}{|l|}{ SPRINT-2 } \\
\hline \multirow[t]{5}{*}{ Naïve patients } & One or more $\mathrm{AE}$ & $98 \%$ & $99 \%$ & $99 \%$ \\
\hline & Serious $A E$ & $9 \%$ & $11 \%$ & $12 \%$ \\
\hline & Dose modification due to $A E$ & $26 \%$ & $40 \%$ & $35 \%$ \\
\hline & Discontinuation due to $\mathrm{AE}$ & $16 \%$ & $12 \%$ & $16 \%$ \\
\hline & Death & $1 \%$ & $<1 \%$ & $<1 \%$ \\
\hline \multicolumn{5}{|l|}{ RESPOND-2 } \\
\hline \multirow[t]{5}{*}{ Previously-treated patients } & One or more $\mathrm{AE}$ & $96 \%$ & $99 \%$ & $100 \%$ \\
\hline & Serious AE & $5 \%$ & $10 \%$ & $14 \%$ \\
\hline & Dose modification due to $A E$ & $14 \%$ & $29 \%$ & $33 \%$ \\
\hline & Discontinuation due to $\mathrm{AE}$ & $2 \%$ & $8 \%$ & $12 \%$ \\
\hline & Death & $0 \%$ & $1 \%$ & $0 \%$ \\
\hline
\end{tabular}

Note: Data obtained from Poordad et al and Bacon et al. ${ }^{36,37}$

Abbreviation: $\mathrm{AE}$, adverse event. 
Table 5 Major adverse events related to boceprevir treatment in phase III clinical trials*

\begin{tabular}{|c|c|c|c|c|}
\hline Trial & Adverse event & $\begin{array}{l}\text { Control } \\
\text { (group I) }\end{array}$ & $\begin{array}{l}\text { Response-guided } \\
\text { therapy (group 2) }\end{array}$ & $\begin{array}{l}\text { Fixed-duration } \\
\text { therapy (group 3) }\end{array}$ \\
\hline \multicolumn{5}{|l|}{ SPRINT-2 } \\
\hline \multirow[t]{6}{*}{ Naïve patients } & Anemia & $29 \%$ & $49 \%$ & $49 \%$ \\
\hline & Dysgeusia & $18 \%$ & $37 \%$ & $43 \%$ \\
\hline & Decreased hemoglobin concentration at week $12(\mathrm{~g} / \mathrm{dL})^{\S}$ & -3.0 & -4.0 & -3.9 \\
\hline & Decreased hemoglobin concentration at week $24(\mathrm{~g} / \mathrm{dL})^{\S}$ & -3.1 & -4.1 & -3.9 \\
\hline & Erythropoietin use & $24 \%$ & $43 \%$ & $43 \%$ \\
\hline & $\begin{array}{l}\text { Decreased absolute neutrophile count } \\
\left(500 \text { to }<750 \text { per } \mathrm{mm}^{3}\right)\end{array}$ & $14 \%$ & $24 \%$ & $25 \%$ \\
\hline \multicolumn{5}{|l|}{ RESPOND-2 } \\
\hline \multirow[t]{5}{*}{ Previously-treated patients } & Anemia & $20 \%$ & $43 \%$ & $46 \%$ \\
\hline & Dysguesia & $11 \%$ & $43 \%$ & $45 \%$ \\
\hline & Decreased hemoglobin concentration at week $12(\mathrm{~g} / \mathrm{dL})^{\S}$ & -2.89 & -4.02 & -3.96 \\
\hline & Decreased hemoglobin concentration at week $24(\mathrm{~g} / \mathrm{dL})^{\S}$ & -2.69 & -4.36 & -4.31 \\
\hline & Erythropoietin use & $21 \%$ & $41 \%$ & $46 \%$ \\
\hline
\end{tabular}

Notes: *Data are presented as percentages from the total number of subjects per group (except $\S$ ). Only adverse events associated with a $P$ value $<0.00 I$ are reported in this table; ${ }^{\S}$ data are expressed as mean change in hemoglobin concentration from baseline. Data drawn from Poordad et al and Bacon et al. ${ }^{36,37}$

associated with an improved rapid virological response (negativity of serum HCV RNA at week 4 of therapy), complete early virological response, and sustained virological response. A sustained virological response was observed in $69 \%$ of patients with the CC IL28B type versus $33 \%$ and $27 \%$ with the CT and TT IL28B types, respectively. ${ }^{45}$ African Americans had the CC IL28B type less often, which explains the lower response to PEGIFN- $\alpha$-ribavirin in these patients. ${ }^{45}$ However, sustained virological response rates were lower even in African American patients with the CC genotype. In this study, African American ethnicity remained an independent negative predictor of outcome, ${ }^{45}$ suggesting the presence of other as yet undetected genetic variants that influence the treatment response in African Americans. The CC IL-28B genotype also increased the proportion of patients who attained a rapid virological response. However, in patients who achieved a rapid virological response, sustained virological response rates were high, independent of $I L-28 B$ single nucleotide polymorphism. While the most important prognostic factor for sustained virological response remains rapid virological response, ${ }^{45}$ this cannot be known before therapy, unlike with the $I L 28 B$ polymorphism. Moreover, the $\mathrm{CC}$ genotype is also indicative of a sustained virological response in patients treated with PEG-IFN- $\alpha$-ribavirin without a rapid virological response. Interestingly, the effect of $I L 28 B$ variants was retrospectively evaluated in both Phase III studies evaluating triple therapy that were ongoing at the time of discovery of the $I L 28 B$ variants. ${ }^{39,46} \mathrm{In}$ both trials, $I L 28 B$ CC polymorphism was a strong predictor of viral response at weeks 4 and 8 . In total, $80 \%-90 \%$ of naïve and treatment-experienced patients with $I L 28 B$ CC polymorphism qualify for a shorter duration of PEG-IFN$\alpha$-ribavirin and boceprevir. Noteworthy is that the response to lead-in treatment with PEG-IFN- $\alpha$-ribavirin was the strongest predictor of a sustained virological response, with this parameter being superior to all other factors, including IL28B polymorphism. In patients with IL28B CT and TT polymorphisms who responded more poorly, addition of boceprevir significantly improved sustained virological response rates. In naïve patients, the sustained virological response increased in the most difficult-to-treat $I L 28 B$ CT and TT patients from $28 \%$ to $27 \%$, respectively, in the PEGIFN- $\alpha$-ribavirin control group, to $65 \%$ in the IL28B CT/ response-guided therapy group, and to $71 \%$ in the $I L 28 B$ $\mathrm{CT} /$ fixed-duration therapy group. The sustained virological response rate was $55 \%$ in the $I L 28 B \mathrm{TT} /$ response-guided therapy group and $59 \%$ in the $I L 28 B \mathrm{TT} /$ fixed-duration therapy group. ${ }^{47}$

\section{Inosine triphosphatase}

Ribavirin-induced hemolytic anemia is a common adverse event in patients treated with standard of care and has been reported in $20 \%$ of patients. ${ }^{48}$ Two single nucleotide polymorphisms of the inosine triphosphatase (ITPA) gene, which are responsible for inosine triphosphatase deficiency, have been found to be associated with protection from ribavirin-induced hemolytic anemia and a decreased need for ribavirin dose reduction during therapy. Another study did not report an association between ITPA polymorphism 
and sustained virological response, but the relatively small number of patients evaluated might represent a limitation. ${ }^{49,50}$ In the boceprevir trials, anemia increased when boceprevir was added. Anemia was reported in $29 \%$ of controls and in $49 \%$ of boceprevir groups. ${ }^{51}$ In these studies, erythropoietin administration was allowed, with $43 \%$ of patients in the boceprevir arms receiving erythropoietin in comparison with $24 \%$ in the control group. ${ }^{36}$ In the boceprevir studies, reduction of the ribavirin dose and administration of erythropoietin were recommended when hemoglobin fell below $10 \mathrm{~g} / \mathrm{dL}$, but decisions were made at the discretion of the investigator.

Despite the frequency of anemia, drug discontinuation due to anemia occurred in only $1 \%$ of patients included in the boceprevir trials. ${ }^{36,37}$ Results of the influence of ITPA gene variants, which may help to predict susceptibility to anemia, were not reported for either of the studies. The best way to manage anemia remains to be determined. Indeed, there is a possibly increased risk of thromboembolic and adverse cardiac events in patients treated with erythropoietin. A randomized trial comparing ribavirin dose reduction with administration of erythropoietin for the management of anemia in patients with chronic hepatitis $\mathrm{C}$ receiving boceprevir and PEG-IFN- $\alpha$-ribavirin has shown similar sustained virological response rates and safety profiles in both groups. ${ }^{51}$ Therefore, reduction of the ribavirin dose in patients treated with PEG-IFN- $\alpha$-ribavirin and boceprevir appears to be an appropriate way to manage anemia.

\section{Programmed cell death-I molecule}

Chronic HCV infection is characterized by impaired effector functions of virus-specific T lymphocytes. Programmed cell death-1 (PD-1) is a regulatory molecule expressed on the surface of CD4+ T cells, CD8+ T cells, and natural killer cells. ${ }^{52}$ Its upregulation leads to cell exhaustion in terms of proliferation, cytokine secretion, and cytotoxic activity. PD-1 plays a major role in viral infections, because its expression is lower in individuals who resolve the infection compared with those who develop chronic disease. ${ }^{53}$ Moreover, overexpression of PD-1 has been shown to be associated with failure of response to treatment with PEG-IFN- $\alpha$-ribavirin. ${ }^{52}$ Very recently, the $P D-1.3 / \mathrm{A}$ allele has been shown to be strongly associated with a sustained virological response in patients treated with PEG-IFN- $\alpha$-ribavirin. ${ }^{54} P D-1.3$ and $I L 28 B$ seem to have a higher predictive value than HCV genotype, with a sustained virological response being achieved in $90 \%$ of genotype $1 \mathrm{HCV}$-infected patients with the $I L 28 B$ CC genotype and the $P D-1.3 /$ A allele. ${ }^{54}$

\section{Implications for clinical use: patient considerations}

The main findings on the use of boceprevir for the treatment of chronic hepatitis $\mathrm{C}$ in patients infected with genotype 1 is the marked increase in sustained virological response rates in both previously untreated patients and nonresponders to PEG-IFN- $\alpha$-ribavirin. In addition, duration of therapy may be shortened to 28 weeks in the majority of previously untreated patients. Based on these results, patients with HCV genotype 1 infection are eligible for triple therapy if they have a clinical profile similar to that of patients included in the studies conducted so far. Indeed, triple therapy with boceprevir and PEG-IFN- $\alpha$-ribavirin has not been evaluated until now, and only in a few studies of patients with decompensated cirrhosis, HIV coinfection, or liver transplantation. ${ }^{55}$ Therefore, triple therapy including boceprevir should be avoided in these clinical situations unless in the context of carefully controlled clinical trials, due to the limited safety and efficacy data available for these difficult-to-treat patients. Although triple therapy is more effective, the side effects of boceprevir are additive to those of PEG-IFN- $\alpha$-ribavirin, with an increase in potentially severe adverse events. The increasing number of adverse effects and complexity of triple therapy, with the requirement to take $12 \times 200 \mathrm{mg}$ capsules of boceprevir daily in three doses every 8 hours with food to increase absorption continue to limit the number of patients who can benefit from therapy. Finally, the decision to treat should be made on an individual basis, taking into account the severity and therefore the prognosis of the liver disease, the efficacy of therapy, as predicted by careful evaluation, and the side effects that may arise in a particular patient with a particular personal history. Boceprevir trials were designed with the concept of individualized and response-guided therapy and based treatment decisions on how rapidly patients responded to treatment. Predictors of response, determined at baseline, were treatment with boceprevir, nonblack ethnicity, baseline HCV RNA $\leq 400,000 \mathrm{UI} / \mathrm{mL}$, age $\leq 40$ years, absence of cirrhosis, and use of statins. ${ }^{36}$

Retrospective analysis of $I L 28 B$ polymorphisms showed that the IL28B CC genotype was more strongly associated with a sustained virological response than any other baseline factor, and thus identifies patients who may benefit from shorter-term treatment with a success rate higher than $80 \%{ }^{46}$ These patients with a very good response profile have the best benefit-risk ratio. In such patients, the principal advantage of triple therapy is to shorten the treatment duration, although the benefit of standard PEG-IFN- $\alpha$-ribavirin therapy for 
24 weeks is not known, but may have similar efficacy. The discovery of $I L 28 B$ polymorphism has brought the treatment of hepatitis $\mathrm{C}$ into the era of pharmacogenomics, with the implementation of proposals to take into account this parameter in the therapeutic algorithm 3 years after its discovery. ${ }^{56}$ However, the clinical usefulness of $I L 28 B$ variants needs further evaluation in prospective trials to show the relevance of the favorable $I L 28 B$ genotype in clinical practice.

Another and more important predictive factor of sustained virological response was a $\geq 1 \log _{10}$ decrease of HCV RNA at week 4 . This factor was more strongly predictive of a sustained virological response than $I L 28 B$ polymorphism, with $80 \%$ of patients in the different groups achieving a sustained virological response regardless of the $I L 28 B$ genotype. ${ }^{46}$ The lead-in period, which consists of 4 weeks of administration of PEG-IFN- $\alpha$-ribavirin before adding boceprevir, has the advantage of evaluating tolerability and compliance with PEG-IFN- $\alpha$-ribavirin therapy before administration of triple therapy which is more complex and difficult to endure. Finally, the decision to treat with triple therapy is also based on factors that may not have been evaluated in clinical trials, such as severity of disease, tolerability of a previous PEGIFN- $\alpha$-ribavirin regimen, and comorbidities, in particular a cardiac history in older patients. ${ }^{57}$

Thus, individualized approaches to HCV therapy leading to personalized therapy are based on host factors which are prominent before therapy, as well as on viral parameters and, most importantly, on HCV genotype, which limits the efficacy of first-generation direct-acting antiviral agents for a specific genotype, such as boceprevir for genotype 1. Host factors include $I L 28 B$ variants, comorbidities, adherence issues, drug-drug interactions, HIV coinfection, and decompensated liver disease. However, as mentioned earlier, some of these factors have not been evaluated in clinical trials, making the assessment of the risk-benefit ratio more difficult in routine clinical practice.

Moreover, the relevance of other important potential factors, such as the ITPA gene which may protect against anemia occurring during PEG-IFN- $\alpha$-ribavirin therapy, have not been evaluated in the context of triple therapy including boceprevir, despite the high frequency of anemia in the boceprevir trials. The individualization of treatment should also take into account the rapidly changing therapeutic landscape that could indicate the potential efficacy of interferon-free regimens combining direct-acting antiviral agents only, as is the case in treatment for HIV. ${ }^{58,59}$ Thus, patients who have features predicting a poor response to boceprevir and PEG-IFN- $\alpha$-ribavirin or who have had a poor response after the lead-in period may benefit from better therapies, once they become available.

Personalized medicine is a prerequisite for successful treatment, because boceprevir combined with PEG-IFN$\alpha$-ribavirin is effective but also has significant side effects and costs. Multiple host and virological parameters have to be assessed precisely before and during therapy. Its success will be driven by attention to the requirements of this new standard of care, which includes appropriate dosing, management, and anticipation of side effects, as well as strict adherence to rules for cessation (Figure 3) ${ }^{60}$ Careful patient education should give complete information on treatment to ensure good adherence and patient participation, thereby increasing the chances of treatment being successful.

\section{Acknowledgment}

We thank Mirjam Zeisel (Inserm Unit 748) for having carefully reviewed the manuscript, and for her suggestions and helpful comments.

\section{Disclosure}

FH reports receiving payment for lectures from Merck and Janssen, reimbursement for meeting expenses from Merck, Janssen, and Gilead, and consulting fees from Transgene, Gilead, BMS Cytheris, and Roche. MD reports receiving payment for medical education from MSD, Roche, BMS, and Gilead, and payment for board membership from MSD. CL and TFB do not report any potential conflicts of interest relevant to this work.

\section{References}

1. Choo QL, Kuo G, Weiner AJ, Overby LR, Bradley DW, Houghton M. Isolation of a cDNA clone derived from a blood-borne non-A, non-B viral hepatitis genome. Science. 1989;244:359-362.

2. Lauer GM, Walker BD. Hepatitis C virus infection. N Engl J Med. 2001; 345:41-52.

3. World Health Organization. Hepatitis C. Fact sheet N 164 . July 2012. [Webpage on the Internet] http://www.who.int/mediacentre/factsheets/ fs164/en/index.html. Accessed April 14, 2012.

4. Armstrong GL, Wasley A, Simard EP, McQuillan GM, Kuhnert WL, Alter MJ. The prevalence of hepatitis C virus infection in the United States, 1999 through 2002. Ann Intern Med. 2006;144:705-714.

5. Moradpour D, Penin F, Rice CM. Replication of hepatitis C virus. Nat Rev Microbiol. 2007;5:453-463.

6. Seeff LB. Natural history of chronic hepatitis C. Hepatology. 2002; 36(5 Suppl 1):S35-S46

7. Ghany MG, Strader DB, Thomas DL, Seeff LB. Diagnosis, management, and treatment of hepatitis C: an update. Hepatology. 2009;49:1335-1374.

8. Hoofnagle JH, Mullen KD, Jones DB, et al. Treatment of chronic non-A, non-B hepatitis with recombinant human alpha interferon. A preliminary report. N Engl J Med. 1986;315:1575-1578.

9. Shiratori Y, Imazeki F, Moriyama M, et al. Histologic improvement of fibrosis in patients with hepatitis $\mathrm{C}$ who have sustained response to interferon therapy. Ann Intern Med. 2000;132:517-524. 
10. Imai $Y$, Kasahara $A$, Tanaka $H$, et al. Interferon therapy for aged patients with chronic hepatitis $\mathrm{C}$ : improved survival in patients exhibiting a biochemical response. J Gastroenterol. 2004;39:1069-1077.

11. Kasahara A, Tanaka H, Okanoue T, et al. Interferon treatment improves survival in chronic hepatitis $\mathrm{C}$ patients showing biochemical as well as virological responses by preventing liver-related death. J Viral Hepat. 2004;11:148-156

12. Katze MG, He Y, Gale M Jr. Viruses and interferon: a fight for supremacy. Nat Rev Immunol. 2002;2:675-687.

13. Pawlotsky JM. Therapy of hepatitis C: From empiricism to eradication. Hepatology. 2006;43 Suppl 1:S207-S220.

14. Reichard O, Andersson J, Schvarcz R, Weiland O. Ribavirin treatment for chronic hepatitis C. Lancet. 1991;337:1058-1061.

15. Di Bisceglie AM, Shindo M, Fong TL, et al. A pilot study of ribavirin therapy for chronic hepatitis C. Hepatology. 1992;16:649-654.

16. Brillanti S, Garson J, Foli M, et al. A pilot study of combination therapy with ribavirin plus interferon alfa for interferon alfa-resistant chronic hepatitis C. Gastroenterology. 1994;107:812-817.

17. Poynard T, Marcellin P, Lee SS, et al. Randomised trial of interferon alpha2b plus ribavirin for 48 weeks or for 24 weeks versus interferon alpha2b plus placebo for 48 weeks for treatment of chronic infection with hepatitis $\mathrm{C}$ virus. International Hepatitis Interventional Therapy Group (IHIT). Lancet. 1998;352:1426-1432.

18. Lohmann V, Körner F, Koch J, Herian U, Theilmann I, Bartenschlager R. Replication of subgenomic hepatitis C virus RNAs in a hepatoma cell line. Science. 1999;285:110-113.

19. Lindenbach BD, Rice CM. Flaviviridae: The viruses and their replication. In: Fields Virology. Volume 1. 4th ed. Philadelphia, PA: Lippincott Williams \& Wilkins; 2001

20. Kim JL, Morgenstern KA, Lin C, et al. Crystal structure of the hepatitis $\mathrm{C}$ virus NS3 protease domain complexed with a synthetic NS4A cofactor peptide. Cell. 1996;87:343-355.

21. Love RA, Parge HE, Wickersham JA, et al. The crystal structure of hepatitis C virus NS3 proteinase reveals a trypsin-like fold and a structural zinc binding site. Cell. 1996;87:331-342.

22. Lamarre D, Anderson PC, Bailey M, et al. An NS3 protease inhibitor with antiviral effects in humans infected with hepatitis $\mathrm{C}$ virus. Nature. 2003;426:186-189.

23. Malcolm BA, Liu R, Lahser F, et al. SCH 503034, a mechanism-based inhibitor of hepatitis $\mathrm{C}$ virus NS3 protease, suppresses polyprotein maturation and enhances the antiviral activity of alpha interferon in replicon cells. Antimicrob Agents Chemother. 2006;50:1013-1020.

24. Merck. Victrelis (boceprevir) prescribing information. May 2011 Available at: http://www.merck.com/product/usa/pi_circulars/v/ victrelis/victrelis_pi.pdf. Accessed July 10, 2012.

25. FDA US Food and Drug Administration. Drug approval package. Victrelis (boceprevir). Available at http://www.accessdata.fda.gov/ drugsatfda_docs/nda/2011/2022580rig1s000TOC.cfm. Accessed December 14, 2011

26. Ghosal A, Yuan Y, Tong W, et al. Characterization of human liver enzymes involved in the biotransformation of boceprevir, a hepatitis C virus protease inhibitor. Drug Metab Dispos. 2011;39:510-521.

27. Flockhart DA, Tanus-Santos JE. Implications of cytochrome P450 interactions when prescribing medication for hypertension. Arch Intern Med. 2002;162:405-412.

28. Kiser JJ, Burton JR, Anderson PL, Everson GT. Review and management of drug interactions with boceprevir and telaprevir. Hepatology. 2012;55:1620-1628.

29. Zeuzem S, Sarrazin C, Rouzier R, et al. Antiviral activity of SCH 503034 , a $\mathrm{HCV}$ protease inhibitor, administered as monotherapy in hepatitis $\mathrm{C}$ genotype-1 (HCV-1) patients refractory to pegylated interferon (PEG-IFN-alpha). Hepatology. 2005;42 Suppl 1:S233-S234.

30. Susser S, Welker MW, Zettler M, et al. Clonal analysis of mutations selected in the HCV NS3 protease domain of genotype 1 nonresponders treated with boceprevir (SCH503034). J Hepatol. 2008; 48 Suppl 2:S29.
31. Flint M, Mullen S, Deatly AM, et al. Selection and characterization of hepatitis $\mathrm{C}$ virus replicons dually resistant to the polymerase and protease inhibitors HCV-796 and boceprevir (SCH 503034). Antimicrob Agents Chemother. 2009;53:401-411.

32. Pawlotsky JM. Treatment of hepatitis C: don't put all your eggs in one basket! Gastroenterology. 2007;132:1611-1615.

33. Sarrazin C, Rouzier R, Wagner F, et al. SCH 503034, a novel hepatitis C virus protease inhibitor, plus pegylated interferon alpha- $2 \mathrm{~b}$ for genotype 1 nonresponders. Gastroenterology. 2007;132:1270-1278.

34. Kwo PY, Lawitz EJ, McCone J, et al. Efficacy of boceprevir, an NS3 protease inhibitor, in combination with peginterferon alfa- $2 b$ and ribavirin in treatment-naive patients with genotype 1 hepatitis $\mathrm{C}$ infection (SPRINT-1): an open-label, randomised, multicentre phase 2 trial. Lancet. 2010;376:705-716.

35. Schiff E, Poordad F, Jacobson I, et al. Boceprevir (B) combination therapy in null responders (NR): response dependent on interferon responsiveness. J Hepatol. 2008;48 Supp1 2:S46.

36. Poordad F, McCone J, Bacon BR, et al. Boceprevir for untreated chronic HCV genotype 1 infection. N Engl J Med. 2011;364:1195-1206.

37. Bacon BR, Gordon SC, Lawitz E, et al. Boceprevir for previously treated chronic HCV genotype 1 infection. N Engl J Med. 2011;364: 1207-1217.

38. Brass C, Barnard RJO, Howe JA, et al. Sustained virologic response and boceprevir resistance-associated variants observed in patients infected with HCV genotype $1 \mathrm{a} / 1 \mathrm{~b}$ when treated with boceprevir plus peginterferon alfa-2b/ribavirin. J Hepatol. 2011;54 Suppl 1:S471-S472.

39. Bronowicki JP, Davis M, Flamm S, et al. Sustained virologic response $(\mathrm{SVR})$ in prior peginterferon/ribavirin (PR) treatment failures after retreatment with boceprevir (BOC)-+-PR: the provide study interim results. J Hepatol. 2012;56 Suppl 2:S6.

40. Vierling JM, Ralston R, Lawitz EJ, et al. Long-term outcomes following combination treatment with boceprevir plus peg-intron/ribavirin $(\mathrm{P} / \mathrm{R})$ in patients with chronic hepatitis C, genotype 1 (CHC-G1). J Hepatol. 2010;52 Suppl 1:S470-S471.

41. Jacobson IM, Marcellin P, Zeuzem S, et al. Refinement of stopping rules during treatment of hepatitis $\mathrm{C}$ genotype 1 infection with boceprevir combined with peginterferon/ribavirin. Hepatology. May 22, 2012. [Epub ahead of print.]

42. Conjeevaram HS, Fried MW, Jeffers LJ, et al. Peginterferon and ribavirin treatment in African American and Caucasian American patients with hepatitis C genotype 1. Gastroenterology. 2006;131:470-477.

43. Ge D, Fellay J, Thompson AJ, et al. Genetic variation in IL28B predicts hepatitis C treatment-induced viral clearance. Nature. 2009;461: 399-401.

44. Thomas DL, Thio CL, Martin MP, et al. Genetic variation in IL28B and spontaneous clearance of hepatitis C virus. Nature. 2009;461: 798-801.

45. Thompson AJ, Muir AJ, Sulkowski MS, et al. Interleukin-28B polymorphism improves viral kinetics and is the strongest pretreatment predictor of sustained virologic response in genotype 1 hepatitis $\mathrm{C}$ virus. Gastroenterology. 2010;139:120-129.

46. Poordad F, Bronowicki JP, Gordon SC, et al. Factors that predict response of patients with hepatitis $\mathrm{C}$ virus infection to boceprevir. Gastroenterology. May 21, 2012. [Epub ahead of print.]

47. Kwo PY. Phase III results in genotype 1 naïve patients: predictors of response with boceprevir and telaprevir combined with pegylated interferon and ribavirin. Liver Int. 2012;32 Suppl 1:S39-S43.

48. Fried MW, Shiffman ML, Reddy KR, et al. Peginterferon alfa-2a plus ribavirin for chronic hepatitis C virus infection. N Engl J Med. 2002;347: 975-982.

49. Fellay J, Thompson A, Ge D, et al. ITPA gene variants protect against anaemia in patients treated for chronic hepatitis C. Nature. 2010;464: 405-408.

50. Thompson AJ, Fellay J, Patel K, et al. Variants in the ITPA gene protect against ribavirin-induced hemolytic anemia and decrease the need for ribavirin dose reduction. Gastroenterology. 2010;139:1181-1189. 
51. Poordad F, Lawitz EJ, Reddy KR, et al. A randomized trial comparing ribavirin dose reduction versus erythropoietin for anemia management in previously untreated patients with chronic hepatitis $\mathrm{C}$ receiving boceprevir plus peginterferon/ribavirin. J Hepatol. 2012; 56 Suppl 2:S559.

52. Golden-Mason L, Klarquist J, Wahed AS, Rosen HR. Cutting edge: Programmed death-1 expression is increased on immunocytes in chronic hepatitis $\mathrm{C}$ virus and predicts failure of response to antiviral therapy: race-dependent differences. J Immunol. 2008;180:3637-3641.

53. Urbani S, Amadei B, Tola D, et al. PD-1 expression in acute hepatitis $\mathrm{C}$ virus $(\mathrm{HCV})$ infection is associated with $\mathrm{HCV}$-specific CD8 exhaustion. J Virol. 2006;80:11398-11403.

54. Vidal-Castiñeira JR, López-Vázquez A, Alonso-Arias R, et al. A predictive model of treatment outcome in patients with chronic HCV infection using IL28B and PD-1 genotyping. J Hepatol. 2012;56: 1230-1238.

55. Sulkowski M, Pol S, Cooper C, et al. Boceprevir + pegylated interferon + ribavirin for the treatment of $\mathrm{HCV} / \mathrm{HIV}$-coinfected patients: end of treatment (week 48) interim results. Abstract 47 presented at the 19 th Conference on Retroviruses and Opportunistic Infections, Seattle, WA; March 5-8, 2012.

56. Ramachandran P, Fraser A, Agarwal K, et al. UK consensus guidelines for the use of the protease inhibitors boceprevir and telaprevir in genotype 1 chronic hepatitis $\mathrm{C}$ infected patients. Aliment Pharmacol Ther. 2012;35:647-662.

57. Iwasaki Y, Ikeda H, Araki Y, et al. Limitation of combination therapy of interferon and ribavirin for older patients with chronic hepatitis $\mathrm{C}$. Hepatology. 2006;43:54-63.
58. Lawitz E, Poordad F, Kowdley KV, et al. A 12-week interferon-free regimen of ABT-450/R, ABT-072, and ribavirin was well tolerated and achieved sustained virologic response in $91 \%$ of treatment-naive HCV IL28B-CC genotype-1-infected subjects. J Hepatol. 2012; 56 Suppl 2:S7.

59. Sulkowski M, Rodriguez-Torres M, Lawitz E, et al. High SVR rate in treatment-naïve HCV genotype $1 \mathrm{a}$ and $1 \mathrm{~b}$ patients treated for 12 weeks with an interferon-free all-oral quad regimen: interim results. $J$ Hepatol. 2012;56 Suppl 2:S559.

60. Approval of Victrelis (boceprevir) by US Food and Drug Administration. May 2011. Available at: http://www.fda.gov/ForConsumers/ ByAudience/ForPatientAdvocates/ucm255413.htm. Accessed July 10, 2012.

61. Barritt AS, Fried MW. Maximizing opportunities and avoiding mistakes in triple therapy for hepatitis C virus. Gastroenterology. 2012;14 1314-1323.

62. Klibanov OM, Vickery SB, Olin JL, et al. Boceprevir: a novel NS3/4 protease inhibitor for the treatment of hepatitis C. Pharmacotherapy. 2012;32:173-190

63. Hulkotte E, Gupta S, Xuan F, et al. Pharmacokinetic interaction between the HCV protease inhibitor boceprevir and cyclosporine and tacrolimus in healthy volunteers. Hepatology. May 11, 2012. [Epub ahead of print.]
Pharmacogenomics and Personalized Medicine

\section{Publish your work in this journal}

Pharmacogenomics and Personalized Medicine is an international, peerreviewed, open access journal characterizing the influence of genotype on pharmacology leading to the development of personalized treatment programs and individualized drug selection for improved safety, efficacy and sustainability. This journal is indexed on the American Chemical

\section{Dovepress}

Society's Chemical Abstracts Service (CAS). The manuscript management system is completely online and includes a very quick and fair peer-review system, which is all easy to use. Visit http://www.dovepress. $\mathrm{com} /$ testimonials.php to read real quotes from published authors. 